\title{
Financiamento de campanha e apoio parlamentar à Agenda Legislativa da Indústria na Câmara dos Deputados
}

\begin{tabular}{c}
\hline \hline Manoel Leonardo Santos \\
Departamento de Ciência Política \\
Faculdade de Filosofia e Ciências Humanas \\
Universidade Federal de Minas Gerais \\
Mariana Batista da Silva \\
Dalson Britto Figueiredo Filho \\
Enivaldo Carvalho da Rocha \\
Departamento de Ciência Política \\
Centro de Filosofia e Ciências Humanas \\
Universidade Federal de Pernambuco \\
\hline \hline
\end{tabular}

Resumo: Qual é o efeito do financiamento de campanha sobre o comportamento do parlamentar? Este artigo analisa a votação dos deputados federais brasileiros (1999-2007) em relação aos projetos de interesse da Confederação Nacional da Indústria (CNI). Metodologicamente, o artigo combina estatística descritiva e multivariada para testar a hipótese de que quanto maior é o financiamento de campanha pela indústria, maior é a cooperação do parlamentar com os interesses desse setor. Foram utilizados análise de cluster e modelos de regressão logístico e de Poisson para estimar o efeito do financiamento de campanha sobre a cooperação do parlamentar com o setor da indústria. Os resultados confirmam parcialmente a hipótese. Não foi encontrada relação entre o financiamento da indústria e a cooperação dos parlamentares, mas confirma-se que a proporção de recursos corporativos influencia positivamente a cooperação dos parlamentares brasileiros com os interesses da CNI, controlando por diferentes variáveis. Esses resultados se alinham à literatura internacional sobre o tema, que encontra uma relação positiva entre contribuições de campanha e comportamento congressual.

Palavras-chave: financiamento de campanha; comportamento legislativo; indústria; CNI

\begin{abstract}
What is the effect of campaign financing on the behavior of congressman? This article analyzes the vote of Brazilian federal deputies (1999-2007) in relation to the projects of interest to the National Confederation of Industry (CNI). Methodologically, the article combines descriptive statistics and multivariate analysis to test the hypothesis that, the higher the campaign financing by industry, greater parliamentary cooperation with the interests of this sector. We use cluster analysis, logistic regression models and Poisson to estimate the effect of campaign financing on cooperation. The results confirm the hypothesis partially. Relationship between industry funding and cooperation of parliamentarians was not found, but it is confirmed that the proportion of corporate resources influences positively the cooperation of Brazilian parliamentarians with the interests of the CNI, controlling by different variables. These results align to the international literature about the subject that finds a positive relationship between campaign contributions and Congressional behavior.
\end{abstract}

Keywords: campaign finance; legislative behavior; industry; National Confederation of Industry 


\section{Introdução}

A pressão de interesses privados sobre instituições governamentais para influenciar as decisões públicas é um tema canônico na ciência política. No que diz respeito aos estudos sobre o Congresso e os grupos de interesse, muitos trabalhos conferem atenção ao impacto das atividades desses grupos sobre o comportamento parlamentar. Grande parte da literatura procura responder às seguintes questões: 1) como e em que medida as doações de campanha influenciam as decisões dos congressistas? e 2) como e em que medida as atividades de lobby influenciam as ações dos parlamentares? (SMITH, 1995). Isso quer dizer que tanto o financiamento de campanha quanto a atividade de lobby são operacionalizados como variáveis independentes, tendo o comportamento do parlamentar como variável dependente.

Especificamente em relação ao efeito do financiamento de campanha, alguns autores encontram que as contribuições, principalmente aquelas feitas pelos PACs ${ }^{1}$, influenciam o comportamento dos congressistas $^{2}$. Em contrapartida, alguns especialistas argumentam que, quando devidamente elaborados, os modelos explicativos mostram que as contribuições de campanha não influenciam o comportamento, ou seja, não exercem efeito significativo sobre os votos dos parlamentares ${ }^{3}$. Entre esses dois extremos, há trabalhos que encontram resultados menos conclusivos, argumentando que há dependência entre as variáveis apenas sob determinadas condições específicas, como, por exemplo, o efeito do financiamento sobre o comportamento seria condicional à ideologia moderada do parlamentar 4 .

Comparativamente, seja em bases teóricas ou empíricas, o Brasil carece de estudos sobre o efeito do financiamento de campanha no comportamento parlamentar. A literatura nacional se limita a analisar o efeito do financiamento sobre o desempenho eleitoral dos candidatos (PEIXOTO, 2004; 2008; 2014; LEMOS; Marcelino; Pederiva, 2010; Portugal; Bugarin, 2003; Cervi, 2009). Na arena legislativa, Mancuso (2007) foi pioneiro em investigar sistematicamente o sucesso de um grupo de interesse no Congresso Nacional. Por sua vez, Santos (2011) analisou a influência do lobby do setor industrial nos resultados políticos que emergem da Câmara dos Deputados. Mas nenhum desses trabalhos considera o efeito do financiamento de campanha sobre o comportamento do parlamentar, que é exatamente o objeto deste artigo.

Para enfrentar a tarefa, foram analisadas as votações nominais em 13 matérias legislativas na Câmara dos Deputados. As votações foram realizadas entre 1999 e 2007, e todas as matérias selecionadas fazem parte da Agenda Legislativa da Indústria, por meio da qual a CNI (Confederação Nacional da Indústria) torna público seu posicionamento sobre matérias prioritárias de interesse do setor.

\footnotetext{
${ }^{1}$ Political Action Commitee. Em 1974, com base no Feca (Federal Election Campaign Act de 1971), a Suprema Corte norte-americana regulamentou a formação desses Comitês como forma de legalizar as contribuições de grupos de interesse. Para uma detalhada evolução da legislação eleitoral, ver Corrado (2005). Para uma discussão aplicada, ver Grier e Munger (1993).

2 Para alguns trabalhos que identificam efeito positivo do financiamento sobre o comportamento parlamentar, ver: Silberman e Durden (1976), Feldstein e Melnick (1984), Frendreis e Waterman (1985), Coughlin (1985), Schroedel (1986), Langbein (1986), Wilhite e Theilmann (1986; 1987), Tosini e Tower (1987), Saltzman (1987), Jones e Kaiser (1987), Masters e Zardkoohi (1988), Wilhite e Paul (1989), Langbein e Lotwis (1990), Neustadtl (1990), Hall e Wayman (1990), Davis (1993), Stratmann (1991; 1995; 1998; 2002), Durden, Shogren e Silberman (1991) e Holian e Krebs (1997).

3 Para exemplos de trabalhos que não identificam efeito do financiamento sobre a atuação parlamentar, ver: Kau e Rubin (1978), Welch (1982), Chappell (1982), Wright (1985), Grenzke (1989), Dow e Endersby (1994), Bronars e Lott (1997) e Wawro (2001).

4 Para exemplos de efeito condicional do financiamento, ver: Chappell (1981), Johnson (1985), Hersch e McDougall (1988), Wright (1990), Abler (1991) e Langbein (1993).
} 
SANTOS, M. L. et al. Financiamento de campanha e apoio parlamentar à Agenda...

Metodologicamente, o artigo combina estatística descritiva e multivariada para testar a hipótese de que quanto maior o financiamento de campanha pela indústria, maior a cooperação do parlamentar com os interesses desse grupo. Para tanto foram utilizadas as seguintes técnicas: análise de cluster para identificar a "bancada da indústria" (grupo de deputados que apresentam maior cooperação com os interesses da indústria), regressão logística para identificar sob quais condições os deputados cooperam e regressão de Poisson para identificar os fatores explicativos do grau de cooperação com os interesses da indústria.

Os resultados não confirmam que o financiamento específico da indústria influencia positivamente a cooperação dos deputados com os interesses do setor, mas as análises apresentam um importante resultado que mostra que o financiamento corporativo (predominantemente de empresas) exerce sim influência positiva sobre a cooperação dos parlamentares em relação à agenda do setor. Esses resultados se alinham à literatura internacional sobre o tema que encontra uma relação positiva entre contribuições de campanha e comportamento congressual, controlando por fatores como a ideologia do parlamentar e o seu background.

O artigo está assim dividido: a próxima seção fundamenta teoricamente a hipótese de trabalho. A terceira seção resume o debate empírico sobre a influência do financiamento de campanha no comportamento parlamentar. A quarta seção apresenta a metodologia e especifica o modelo explicativo e o desenho de pesquisa. Em seguida apresentam-se os resultados. Por último, a conclusão sumariza a discussão e aponta para as limitações e desafios da agenda de pesquisa sobre o tema.

\section{Mercado de políticas: criação de renda ou extração de renda?}

Existe uma vasta literatura que trata da relação entre Estado e interesses privados via regulação (Buchanan; Tullock, 1967; Pincus, 1975; Stigler, 1971; Posner, 1975; Peltzman, 1984; McChesney, 1997). Os principais objetivos dessa literatura são: mostrar que a regulação não é neutra e explicar quem receberá os seus benefícios ou seus custos, que forma ela tomará e quais os seus efeitos sobre a alocação de recursos. Para Stigler (1971), "regulation may be active sought by an industry, or it may be thrust upon it. [...] as a rule, regulation is acquired by the industry and is designed and operated primarily for its benefit" (STIGLER, 1971, p. 23). A Figura 1 ilustra o funcionamento do modelo de Stigler (1971) ${ }^{5}$ :

\footnotetext{
${ }^{5}$ Figura compatível pode ser encontrada originalmente em Tullock (1967).
} 
Figura 1

Teoria econômica da regulação

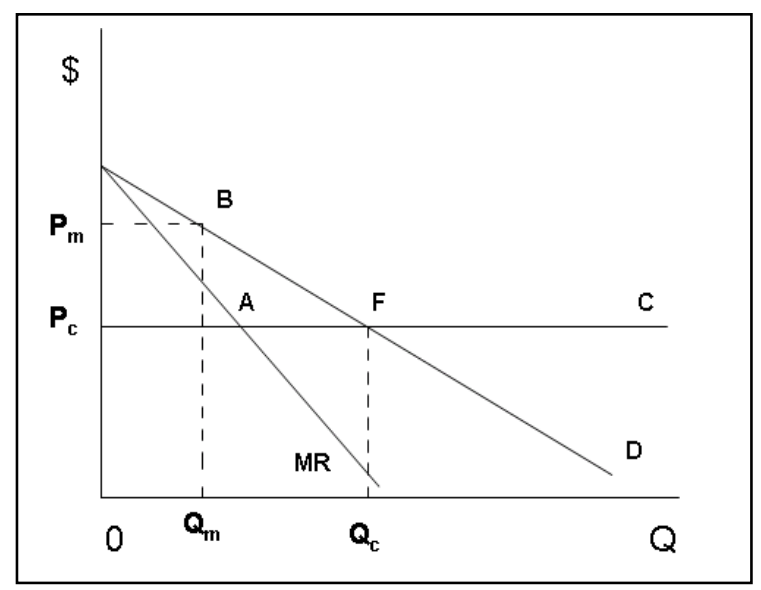

Fonte: Stigler (1971) e Olson (1965).

Na exposição clássica, D representa a demanda por um determinado bem ou serviço. No eixo vertical, tem-se o preço \$ e, no eixo horizontal, tem-se a quantidade Q. Se todas as empresas apresentarem os mesmos custos marginais de produção $\mathrm{C}$, a competição entre as firmas produzirá o resultado $\mathrm{Q}_{c}$ ao preço $\mathrm{P}_{\mathrm{c}}$. Logicamente, nenhuma firma terá interesse em vender seu produto a um preço maior, por exemplo, $\mathrm{P}_{\mathrm{m}}$, já que sua lucratividade será negativamente influenciada. Todavia, é possível que um preço mais elevado $\left(P_{m}\right)$ do que o preço de equilíbrio $\left(P_{c}\right)$ seja estabelecido por meio de uma regulação fixada pelo Estado, através, por exemplo, de barreiras à entrada de novos competidores. A diferença no preço em relação à quantidade vendida, representada pela área do retângulo $P_{c} P_{m} B A$, é renda artificialmente criada para os produtores através da regulação.

O argumento de Stigler tem dois pressupostos básicos. Primeiro, o Estado como entidade coercitiva suprema se constitui numa fonte potencial de recursos ou ameaças a toda atividade econômica. Segundo, admite-se que os sistemas políticos, responsáveis pela disponibilização desses recursos e ameaças, são racionalmente constituídos. Resumindo, "the industry which seeks political power must go to the appropriate seller, the political party" (STIGLER, 1971, p. 12).

Assim, é estabelecida uma relação de troca. Os políticos, para se manterem no poder, necessitam de recursos que vão de votos a contribuições financeiras. O grupo interessado na regulação necessita, para dar um exemplo, de barreiras à entrada de novos competidores. A relação de oferta e demanda está modelada. Como a regulação favorável prevê uma intervenção no processo político, e esta é bastante custosa, a regulação tende a favorecer os grupos mais diretamente interessados, desde que possuam recursos e estejam dispostos a pagar os custos $^{6}$. Landes e Posner (1975) apresentam uma síntese da abordagem econômica sobre os grupos de interesse. Para os autores,

\footnotetext{
${ }^{6}$ Argumento baseado na teoria dos grupos sociais desenvolvida por Olson (1965).
} 
SANTOS, M. L. et al. Financiamento de campanha e apoio parlamentar à Agenda...

\begin{abstract}
In the economists' version of the interest.group theory of government, legislation is supplied to groups or coalitions that outbid rival seekers of favorable legislation. The price that the winning group bids is determined both by the value of legislative protection to the group's members and the group's ability to overcome the free-rider problems that plague coalitions. Payment takes the form of campaign contributions, votes, implicit promises of future favors, and sometimes outright bribes. In short, legislation is "sold" by the legislature and "bought" by the beneficiaries of the legislation (LANDES; POSNER, 1975, p. 877)
\end{abstract}

Em síntese, na medida em que o Estado pode legalmente tributar seus cidadãos, e assim gerar renda, ele se torna alvo dos interesses de diferentes grupos. Esses grupos buscam elevar a quantidade de benefícios auferidos da ação estatal e, para isso, podem se engajar nas mais diversas formas de influenciar as decisões governamentais. Esse é o modelo de criação de renda (rent creation mode). Na terminologia de Olson, esses grupos têm um claro incentivo seletivo positivo para influenciar as decisões públicas. Tem-se aqui a primeira motivação econômica dos grupos de interesse para financiar campanhas eleitorais.

Uma importante contribuição a esse debate foi feita por McChesney (1997) ao demonstrar que os interesses privados não pagam apenas por favores políticos, mas principalmente para evitar desfavores dessa natureza. A Figura 2 ilustra a essência do modelo de extração de renda:

Figura 2

Modelo de extração de renda (rent extraction model) ${ }^{7}$
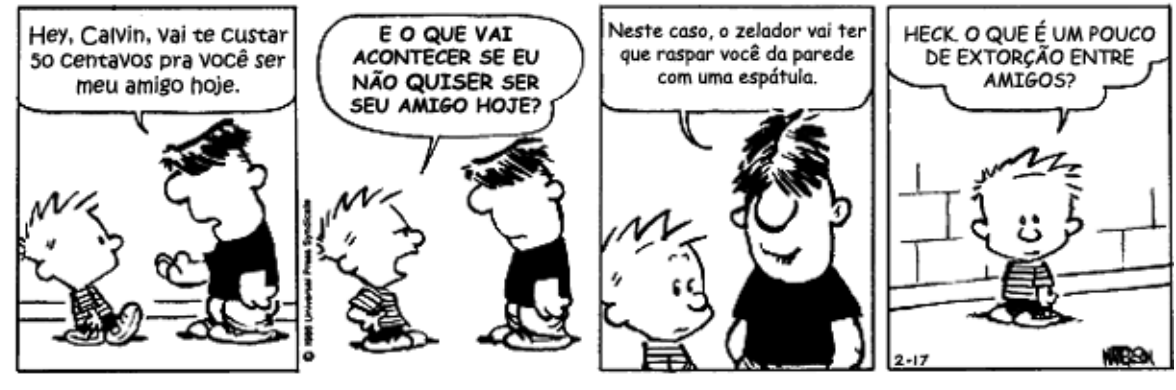

O principal foco do modelo de extração de renda é que "não legislação" e "não regulação" são vendidas no mercado político. Essa noção é simples: visto que o governo pode legalmente tributar e, dessa forma, expropriar riqueza da sociedade, os políticos podem extorquir dinheiro de indivíduos e/ou grupos privados sob a ameaça de expropriar os seus rendimentos. No original,

The rent-extraction model $[\ldots]$ is essentially a model of extortion by politicians. They are paid not to legislate. Status as a legislator confers property right not only to create rents but also to

\footnotetext{
${ }^{7}$ Originalmente, em um dos seus trabalhos, McChesney (1997) utilizou tirinhas para ilustrar o funcionamento do seu modelo. Optou. se por empregar neste artigo o mesmo recurso. A tirinha aqui reproduzida é da série Calvin and Hobbes (no Brasil, Calvin e Haroldo) de autoria de Bill Watterson, que criou a série em 1985 e teve seu trabalho publicado em mais de 2 mil jornais no mundo inteiro durante mais de dez anos.
} 
impose costs that would destroy private rents. In order to protect these returns, private owners have an incentive to strike bargains with legislators, as long as the side payments to politicians are lower than the losses expected from the law threatened (MCCHESNEY, 1997, p. 41).

Por exemplo, o governo pode anunciar o aumento de uma alíquota específica. No modelo de extração de renda, os produtores que seriam prejudicados pela regulação pagarão para evitar a expropriação de seus rendimentos ${ }^{8}$. A Figura 3 ilustra o funcionamento desse modelo:

Figura 3

Modelo de extração de renda para bens substitutos ${ }^{9}$

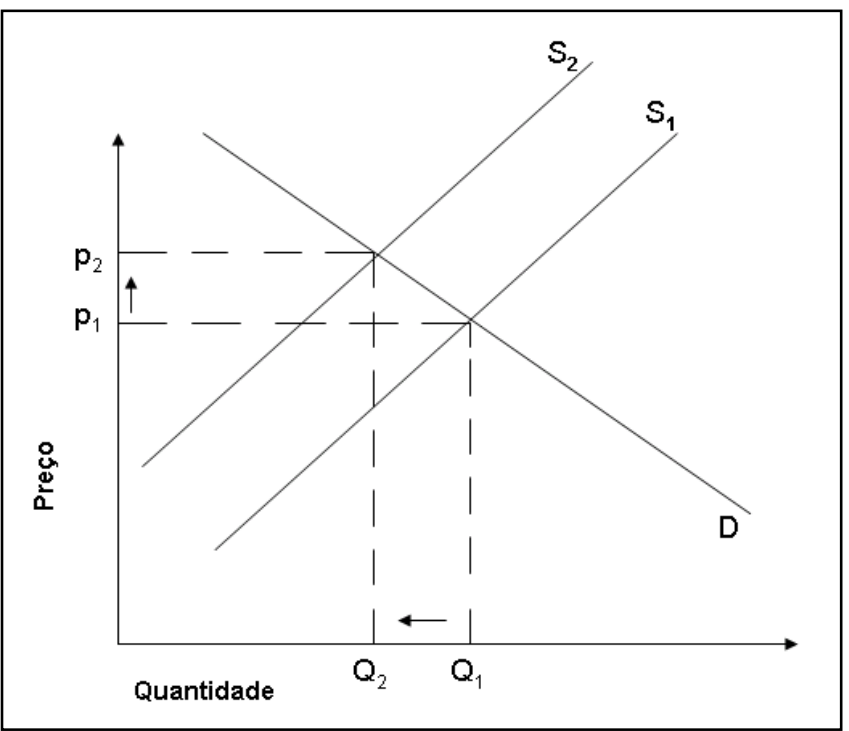

Fonte: McChesney (1997).

Na Figura 3, $P_{1}$ e $Q_{1}$ representam o mercado em equilíbrio. Com a imposição de novos custos (regulação) sobre o bem $X$, o custo marginal de produção é positivamente afetado, influenciando negativamente a oferta $S_{1}$ que passa a ser $S_{2}$. O efeito desse procedimento é o aumento do preço. Em um segundo momento, caso o aumento seja repassado para os consumidores, a demanda pelo bem ou serviço sofrerá decremento $\left(\mathrm{Q}_{1} \rightarrow \mathrm{Q}_{2}\right)$. Como $\mathrm{X}$ e $\mathrm{Y}$ são bens substitutos, os compradores consumirão mais de $\mathrm{Y}$. $\mathrm{A}$ conclusão lógica do modelo de rent extraction é que os produtores que serão prejudicados pela regulação pagarão para evitar a expropriação de seus rendimentos ${ }^{10}$.

\footnotetext{
8 McChesney (1997) afirma que "no one would be so naive as to think that the contributions and tax relief are mere coincidences, causally unrelated. The cash pours in as long as taxation is on the legislative agenda, with money being matched by forbearance in taxing" (MCCHESNEY, 1997, p. 64).

${ }^{9}$ Dois bens para os quais, tudo o mais mantido constante, o aumento no preço de um deles aumenta a demanda pelo outro. Por exemplo, manteiga e margarina; álcool e gasolina etc.

10 Para Olson (1965), uma empresa de determinado setor industrial quererá evitar que novas empresas venham compartilhar de seu mercado e desejará que o maior número possível de empresas já no setor saia dele. Ela quererá que o grupo de empresas de seu setor industrial se reduza até que sobre de preferência apenas uma empresa: ela. Esse é o ideal de monopólio (OLson, 1965, p. 49).
} 
SANTOS, M. L. et al. Financiamento de campanha e apoio parlamentar à Agenda...

Além disso, para que os políticos sejam pagos para não legislar, as ameaças devem ser críveis, pois, caso contrário, haveria poucos incentivos para dissuadir a ação do rent extractor. Nas palavras de Shavell (1993),

\footnotetext{
a person making a threat faces a double problem. On one hand, his threat must be credible. The intended victim must believe there to be a significant chance that the threat will be carried out if and only if he does not accede to it; otherwise, he may have insufficient reason to bow to the will of the threatener. On the other hand, the victim must believe that if he does reward the threatener, he, the victim, will gain thereby and not merely set himself up for further threats [...]. Difficulties in making threats combined with possibilities of miscalculation lead to the risk that demands will be rejected and threats actually executed (SHAVELL, 1993, p. 1878).
}

Tem-se aqui a segunda motivação econômica dos grupos de interesse para financiar campanhas eleitorais. O financiamento buscaria uma não ação ou não intervenção. Para usar os termos do autor, seria money for nothing (MCCHESNEY, 1997). Em vez de buscar a compra de um benefício, o financiamento de campanhas buscaria apenas livrar a indústria de uma intervenção negativa.

Em síntese, seja para se beneficiar das decisões públicas (modelo de criação de renda), seja para evitar desfavores políticos (modelo de extração de renda), os grupos de interesse procurarão influenciar as decisões governamentais. Teoricamente, o primeiro modelo prevê que grupos de interesse trocam financiamento de campanha por legislação favorável. O segundo modelo prevê que os grupos trocam financiamento de campanha por "não ação". Este artigo analisa a relação entre o financiamento de campanha e o comportamento dos parlamentares na votação de matérias de interesse da indústria. A cooperação com a indústria é observada tanto quando o parlamentar vota a favor de uma matéria que é favorável à indústria como quando o parlamentar vota contra uma matéria que é desfavorável a ela. Dessa forma, adota-se uma estratégia metodológica capaz de avaliar, simultaneamente, as previsões dos dois modelos, pois a hipótese testada é de que o financiamento de campanha influencia positivamente a cooperação do parlamentar, seja através da aprovação de políticas favoráveis à indústria, seja através da rejeição de políticas que prejudiquem o setor.

Contudo, antes da análise, é importante reportar os resultados encontrados na literatura empírica sobre a relação entre financiamento de campanha e comportamento parlamentar. Esses resultados nos oferecem fundamentos teóricos que ajudarão a entender as motivações e os limites da hipótese aqui testada. 


\section{Financiamento de campanha e comportamento parlamentar: resultados controversos}

A influência de grupos de interesse sobre o comportamento dos parlamentares mobiliza uma vasta literatura e muitas questões. Quais grupos são bem-sucedidos na tentativa de influenciar os legisladores? Por quê? Quais são as estratégias de influência? Que outros fatores determinam o comportamento dos parlamentares além da influência? A breve revisão a seguir busca mapear as principais variáveis explicativas do enigma da influência dos grupos de pressão sobre o comportamento dos parlamentares, com a finalidade de fundamentar teoricamente o modelo explicativo proposto e testado empiricamente neste artigo.

O argumento central da literatura sobre a influência de grupos de pressão no comportamento dos parlamentares está numa relação de troca (STIGLER, 1971): os políticos, para se manterem no poder, precisam de apoio. O grupo demanda políticas favoráveis. Dessa forma, são duas as principais variáveis explicativas para acesso e influência dos grupos de interesse. A primeira procura estimar, com base no financiamento de campanha, em que medida as contribuições financeiras determinam o comportamento dos deputados. Já a segunda foca especificamente nas atividades de lobby.

No que diz respeito ao financiamento de campanha, que nos interessa mais de perto neste artigo, o senso comum costuma aceitar o argumento que sugere que o financiamento de campanha influencia fortemente as decisões legislativas dos membros do Congresso e que isso contribui para a sobrerrepresentação de interesses especiais e a sub-representação dos interesses dos grupos com menos recursos. Contudo, a revisão dos resultados mais relevantes mostra um campo bastante controverso. Segundo Wawro (2001), a razão de ser desses resultados é que "correlação" é diferente de "relação de causa e feito". Isso porque é natural que as contribuições sejam dadas a linked-mind parlamentares, o que explica a correlação. O problema é, portanto, identificar a presença e, principalmente, a direção da causalidade. De acordo com o autor,

one of the most vexing problems is that it is difficult to untangle the effect of contributions from the effect of a member's predisposition to vote one way or another. That is, PACs contribute to members of Congress who are likely to vote the way PACs favor even in the absence of contributions. A PAC donation to a friendly member might be misconstrued as causing her to vote a particular way, when in fact she would have voted that way to begin with (WAWRO, 2001, p. 563.564).

Segundo levantamento de Figueiredo Filho (2009), 60,5\% da produção encontra efeitos estatisticamente significativos das contribuições de campanha sobre o comportamento legislativo, totalizando 23 artigos. No outro oposto, destaca-se que cerca de $23,7 \%$ da produção não encontra resultados significativos de que as doações de campanha feitas por grupos de interesse influenciam o comportamento parlamentar. Finalmente, observa-se que em 15,8\% dos casos as inferências oferecidas sugerem resultados mistos (mixed results) em que o efeito do financiamento de campanha é condicional, isto é, o efeito do financiamento depende de características da matéria ou do parlamentar. Alguns fatores condicionantes podem ser ressaltados. 
SANTOS, M. L. et al. Financiamento de campanha e apoio parlamentar à Agenda...

O primeiro conjunto de estudos sugere que contribuições de campanha garantem demasiado acesso aos congressistas só quando o tema tem pouca visibilidade (SABATO, 1985; LANGBEIN, 1986; NeUSTADTL, 1990; CLAWSON, 1999), quando a opinião pública é indiferente ao tema ou se posiciona na mesma direção da demanda do grupo de interesse que efetuou a doação (WELCH, 1982; MALBIN, 1984; DenzAu; MUnger, 1986; WILHITE, 1988) e, ainda, quando o público estiver dividido, indiferente ou ignorante sobre o assunto (Welch, 1982; Malbin, 1984; Denzau; Munger, 1986; Frendreis; Waterman, 1985; Langbein; Lotwis, 1990; Magleby; Nelson, 1990; Schlozman; Tierney, 1986; Wilhite, 1988; Conway, 1991). De maneira bastante resumida, os autores sustentam que a exposição do tema na opinião pública relativiza a influência do financiamento de campanha sobre as ações dos parlamentares porque, sob o escrutínio do grande público, a matéria desperta o interesse de múltiplos grupos, que são afetados direta ou indiretamente pela decisão. No limite, esses múltiplos interesses aumentam os custos de o parlamentar apoiar uma matéria que porventura desagrade à sua constituency.

O segundo conjunto de estudos defende que doações mudam a direção do voto do parlamentar (persuasão), principalmente em temas técnicos e especializados (SABATO, 1985; GodWIN, 1988; CHOATE, 1990). O argumento é relativamente simples: temas técnicos e especializados geralmente passam ao largo do interesse público. Além disso, a complexidade torna muito mais difícil o escrutínio por parte de grupos menos informados. Nesse sentido, a assimetria de informação garantiria maior influência aos grupos com mais recursos.

O terceiro sugere que demandas particulares são atendidas em detrimento do interesse público quando os benefícios são concentrados para os grupos de interesse e os custos são difusos pelo eleitorado como um todo (Stratmann, 1991; FLeISHer, 1993; CLAWSON, 1999). O fundamento por trás do argumento encontra raiz no clássico problema de ação coletiva que, segundo Olson (1965), está fortemente relacionado ao tamanho do grupo. Grupos maiores têm mais dificuldades para resolver problemas de ação coletiva do que os grupos menores. Nesse sentido, os grupos menores e mais organizados estão em condições de perceber claramente o que thes afeta, e ensejar ações coletivas para defender seus interesses particulares.

O quarto grupo de trabalhos defende que o financiamento de campanha vai influenciar o comportamento dos parlamentares apenas quando se trata de uma issue com pouca clivagem. Em geral, uma questão não partidária e não ideológica (CONWAY, 1991; FrendREIS; WATERMAN, 1985; MAGLEBY; Nelson, 1990; Malbin, 1984; Mutch, 1988; Schlozman; Tierney, 1986; Welch, 1982; Wright, 1985). Esse argumento leva em consideração que o partido importa para o parlamentar e, mais que isso, que ele age segundo princípios ideológicos que orientam suas posições. Nesse sentido, somam-se ao financiamento de campanha outros determinantes a orientar o comportamento parlamentar.

O quinto e último argumento condiciona a influência do financiamento de campanha a outras ações por parte do grupo. 0 argumento é de que o financiamento de campanha só gerará os efeitos esperados quando o grupo de interesse, além de fazer doações de campanha, também fizer lobby (SABATO, 1985; EVANS, 1986). Em termos resumidos, o financiamento de campanha per se não garante influência, pois ele depende do reforço do lobby. 
Como se vê, a literatura mostra uma série de condições para que se configure a influência do financiamento de campanha sobre o comportamento do parlamentar, minimizando a sua capacidade de se traduzir diretamente em apoio parlamentar. Não é possível incluir como variáveis de controle todos os condicionantes elencados pela literatura, principalmente os que identificam as características da matéria, por ainda não termos esse tipo de informação disponibilizada na literatura brasileira. Sendo assim, incluímos dois fatores que influenciariam o comportamento parlamentar: a ideologia do deputado e seu background. O objetivo é identificar o efeito do financiamento de campanha, dissociando fatores que os tornariam já "predispostos" a cooperar com a indústria, como a sua ideologia e o background.

Além dessas três variáveis independentes, outras variáveis de controle também foram incluídas no modelo. As relações esperadas, as hipóteses e as formas de operacionalização desses conceitos encontram. se na próxima seção.

\section{Metodologia}

Para testar a hipótese da influência do financiamento de campanha sobre o comportamento parlamentar, foram analisados os deputados federais brasileiros nas 51 a (1999-2002) e 52a (2003-2007) legislaturas. A cooperação com a indústria é observada pela votação do parlamentar de acordo com a posição da $\mathrm{CNI}^{11}$, tendo como referência as informações do Legisdata ${ }^{12}$. No processo legislativo brasileiro nem todas as matérias são votadas nominalmente, portanto, as proposições selecionadas correspondem a dois critérios: 1) às matérias identificadas nas Agendas Legislativas da Indústria, a partir das quais se verifica se ela é de interesse do setor e qual seu posicionamento sobre ela; e 2) às matérias que foram objeto de votação nominal no Plenário da Câmara dos Deputados.

Em geral, o parlamentar vota a matéria, mas, sob certas circunstâncias, as votações nominais são sobre requerimentos procedimentais e sobre artigos ou até mesmo termos específicos via "destaque para votação em separado". Como não é possível identificar a posição da CNI nessas situações, optou-se por manter apenas as votações substanciais. A análise foca 13 matérias que obedecem a tais critérios nas duas legislaturas em questão, perfazendo um total de 6.669 observações $^{13}$.

Das 13 matérias, 1 é medida provisória, 3 são projetos de emenda à Constituição, 3 são projetos de lei e 6 são projetos de lei complementar. Como exemplo dos temas envolvidos nessas matérias de interesse da indústria podemos citar a Medida Provisória 107/2003, que altera a legislação tributária, mudando a base de cálculo do Programa de Integração Social/Programa de Formação do Patrimônio do Servidor Público (PIS/Pasep); o Projeto de Emenda à Constituição 407/2001, que prorroga a vigência da

\footnotetext{
11 Criada em 1938, a CNI reúne 27 federações de indústrias nos estados e no Distrito Federal e cerca de 1.300 sindicatos da indústria. A capacidade de coordenação da CNI tem por catalisador um objetivo comum: o aumento da competitividade da indústria nacional através da redução do Custo Brasil (MANCUSO, 2007). A demanda coletiva com vistas ao aumento da competitividade é construída através de um processo articulado e de constante troca de informações, que tem por resultado final a Agenda Legislativa produzida pela Redlndústria. A Redlndústria acompanha todas as iniciativas de interesse da indústria no Congresso e orienta a atuação política da CNI. A Agenda Legislativa lista as proposições de interesse para garantir a competitividade da indústria, promovendo o acompanhamento das propostas e divulgando o posicionamento e as sugestões da CNI (SANTOS, 2011).

12 Sistema de acompanhamento de proposições legislativas que a CNI utiliza para monitorar as atividades legislativas no Congresso Nacional. Agradecemos à CNI que, numa atitude de transparência e de postura colaborativa, disponibilizou os dados, concedeu-nos entrevistas e permitiu o acesso ao Legisdata.

13 Lista com as matérias aqui analisadas e os critérios de seleção pode ser encontrada no Anexo 1.
} 
Contribuição Provisória sobre Movimentação Financeira (CPMF); e o Projeto de Lei de Conversão 72/2003, que acrescenta dispositivos ao Código Tributário Nacional (CTN).

A posição da indústria quanto à matéria é classificada no Legisdata como convergente, convergente com ressalvas, divergente com ressalvas e divergente. Para fins analíticos agrupamos as posições em convergente e divergente. A cooperação com os interesses da indústria é identificada quando o deputado vota de acordo com a demanda da CNI. Isto é, vota a favor quando a posição da indústria é convergente e vota contra quando a posição da indústria é divergente.

O Quadro 1 sumariza as principais características do desenho de pesquisa com o objetivo de garantir a replicabilidade dos resultados ${ }^{14}$ :

\section{Quadro 1 \\ Desenho de pesquisa}

\begin{tabular}{|c|c|}
\hline População & $\begin{array}{l}\text { Deputados federais das } 51^{\mathrm{a}}(1999-2002) \text { e } 52^{\mathrm{a}}(2003-2007) \text { legislaturas, num total } 1.171 \\
\text { parlamentares, totalizando } 9.903 \text { votos em plenário. }\end{array}$ \\
\hline Técnicas & Estatística descritiva, análise de cluster, regressão logística binária e regressão de Poisson. \\
\hline \multirow[b]{2}{*}{ Variáveis } & $\begin{array}{l}\text { Dependente (três especificações): } \\
\text { - Cooperação: assume valor } 1 \text { quando o deputado vota a favor do interesse da indústria e } 0 \\
\text { quando vota contra. Unidade de análise: deputado ina matéria } j \text {. } \\
\text { - Bancada indústria: assume valor } 1 \text { para o cluster de maior cooperação com os interesses } \\
\text { da indústria e } 0 \text { para os demais clusters. Unidade de análise deputado ina legislatura } j \text {. } \\
\text { - Grau de cooperação: número de vezes que o deputado } i \text { votou a favor dos interesses da } \\
\text { indústria na legislatura } j \text {. }\end{array}$ \\
\hline & $\begin{array}{l}\text { Variáveis Independentes: } \\
\text { - Financiamento da indústria: proporção do financiamento de campanha do deputado i na } \\
\text { legislatura joriundo da indústria (SAMUELS, } 2001 \mathrm{a} \text { ). } \\
\text { - Financiamento corporativo: proporção do financiamento de campanha do deputado i na } \\
\text { legislatura joriundo das empresas em geral (SAMUELS, } 2001 \mathrm{a} \text { ). } \\
\text { - Ideologia: posicionamento ideológico dos deputados na escala esquerda-direita (PoWER; } \\
\text { Zucco, 2009). } \\
\text { - Background: variável dummy que assume valor } 1 \text { quando o deputado é classificado como } \\
\text { empresário da indústria e } 0 \text { em caso contrário (SANTOS, 2011). }\end{array}$ \\
\hline
\end{tabular}

Fonte: Elaboração dos autores.

\footnotetext{
14 Para King (1995), o padrão de replicabilidade requer a disponibilização de informação suficiente para compreender, avaliar e replicar os resultados de um determinado trabalho sem informação adicional do autor do estudo. O componente básico do padrão de replicabilidade é que o pesquisador deixe claro o passo a passo de como os dados foram coletados e analisados.
} 
Como mostra o Quadro 1, foram combinadas diferentes técnicas estatísticas: estatística descritiva, análise de cluster, regressão logística e regressão de Poisson. Visando captar diferentes níveis de análise, optou-se pela utilização de três especificações diferentes para a variável dependente (cooperação do parlamentar com a indústria). Na primeira, a matéria é a unidade de análise, e é observado se o deputado coopera ou não coopera com os interesses da indústria. Nesse caso, trata-se de uma variável qualitativa binária que assume valor 1 quando o parlamentar vota a favor dos interesses da indústria e 0 quando vota contra.

Na segunda especificação, a unidade de análise é o parlamentar. Trata-se de uma variável qualitativa binária criada a partir da análise de cluster tendo como referência o número total de vezes que o deputado cooperou com os interesses da indústria ${ }^{15}$. Inicialmente, foi utilizado o método de agrupamento hierárquico e o quadrado da distância euclidiana como medida de distância. Posteriormente, foi utilizado o método de $k$. means clustering e definimos $k=4$ (número de clusters). Depois disso, os clusters foram classificados de acordo com o nível de cooperação com as demandas da CNI: muito forte, forte, médio e fraco. O último procedimento foi criar uma variável dummy que assume valor 1 para os deputados classificados no grupo de maior cooperação (muito forte), denominados como pertencentes à bancada da indústria, e valor 0 para os deputados classificados nos demais clusters.

Por fim, é utilizado o próprio grau de cooperação, ou seja, o número absoluto de vezes que o deputado votou a favor dos interesses da indústria. Aqui se trata de uma variável de contagem. $\mathrm{O}$ uso de três especificações da variável dependente tem por objetivo explicar a cooperação do parlamentar com a indústria, controlando por características tanto da matéria quanto do parlamentar.

Para o caso das duas primeiras variáveis dependentes, o modelo de regressão logística é adequado para estimar a probabilidade de o deputado cooperar com a indústria. Já a terceira especificação da variável dependente, o grau de cooperação, constitui-se no número de vezes que o deputado votou com a indústria e por isso se trata de uma contagem. Como essa variável apresenta somente valores positivos inteiros, o modelo de regressão linear de mínimos quadrados ordinários não se mostra adequado, sendo o modelo de regressão de Poisson mais apropriado (LONG; FREESE, 2001).

Duas especificações foram utilizadas para operacionalizar a principal variável independente (0 financiamento de campanha). A primeira especificação é a proporção do financiamento de campanha do deputado $i$ na legislatura $j$ oriundo da indústria. No modelo, essa variável denomina-se proporção da indústria. A segunda especificação é a proporção do financiamento de campanha do deputado i na legislatura j oriundo do setor corporativo como um todo (todas as doações de pessoa jurídica). No modelo, essa variável denomina-se proporção corporativo. A opção por duas especificações para a variável independente se justifica porque não se conhece a fundo os mecanismos de financiamento de campanha no Brasil, mesmo em se tratando de dados oficiais de financiamento. Nesse sentido, as duas especificações ajudam a explorar mais amplamente o fenômeno. Os dados de financiamento de campanha foram

\footnotetext{
15 O processo para identificação da "bancada da indústria" de acordo com o grau de cooperação com a indústria por meio da análise de cluster é apresentado no Anexo 2.
} 
gentilmente cedidos por Samuels $(2001 b)^{16}$. Como afirmado anteriormente, espera-se que, quanto maior for a proporção de financiamento da indústria e do financiamento corporativo na receita do candidato, maior será sua cooperação com o setor.

Duas outras variáveis independentes compõem o modelo explicativo: a ideologia e o background do parlamentar. O posicionamento ideológico dos deputados na escala esquerda-direita foi atribuído com base nos dados de Power e Zucco (2009). A escala vai de 1 a 10, sendo totalmente de esquerda o parlamentar na posição 1 e totalmente de direita o parlamentar na posição 10. Já a variável background está especificada como uma dummy, que assume valor 1 quando o deputado é classificado como empresário da indústria e 0 em caso contrário (SANTOS, 2011) 17. Quanto mais à direita no espectro ideológico, maior será a cooperação do deputado com o setor. E ser empresário da indústria deve estar positivamente relacionado com a cooperação desse deputado com o setor.

Dadas as características do sistema político brasileiro, marcado pelo papel preponderante do Poder Executivo no processo legislativo e a alta disciplina partidária, algumas variáveis de controle precisaram ser consideradas. No caso do modelo logístico em que a unidade de análise é o voto do deputado na matéria, foram incluídas variáveis de controle sobre a matéria: "Origem" assume valor 1 quando o projeto é de inciativa do Executivo e 0 quando é do Legislativo e "concordância" assume valor 1 quando a CNI e o Executivo têm o mesmo posicionamento e 0 quando o Executivo e a CNI discordam quanto à matéria. Quanto à disciplina, "Disciplinado" indica que o deputado segue a indicação do seu líder partidário. No caso do modelo Poisson, é incluído um controle adicional que indica o número de vezes que o deputado votou naquela legislatura (para controlar pelo fato de os parlamentares votarem em números diferentes de matérias ao longo da Legislatura). A próxima seção apresenta os resultados. Foram incluídos em todos os modelos os controles da legislatura.

\section{Resultados}

Como discutido, o presente artigo analisa a relação entre financiamento de campanha e comportamento parlamentar. Três especificações diferentes da variável dependente são utilizadas: i) a cooperação do parlamentar, tendo a votação na matéria como unidade de análise; ii) a classificação de acordo com a cooperação com as demandas da CNI, sendo o grupo de maior cooperação classificado como a bancada da indústria; e, por último, iii) o grau de cooperação, com base no número de vezes que o parlamentar votou com os interesses da indústria. O Gráfico 1 apresenta a distribuição das três especificações da variável dependente:

\footnotetext{
${ }^{16}$ Agradecemos ao professor David Samuels, da Universidade de Minnesota (EUA), pela colaboração. Não há exagero em afirmar que sem sua cooperação este artigo não seria possível.

17 Agradecemos ao professor Fabiano Santos (Núcleo de Estudos Congressuais - Necon - do lesp.Uerj) e ao professor Renato Boschi (lesp-Uerj). O acesso ao banco de dados sobre as carreiras parlamentares no Brasil foi de extrema importância para a operacionalização dessa variável.
} 


\section{Gráfico 1}

Distribuição das três especificações da variável dependente

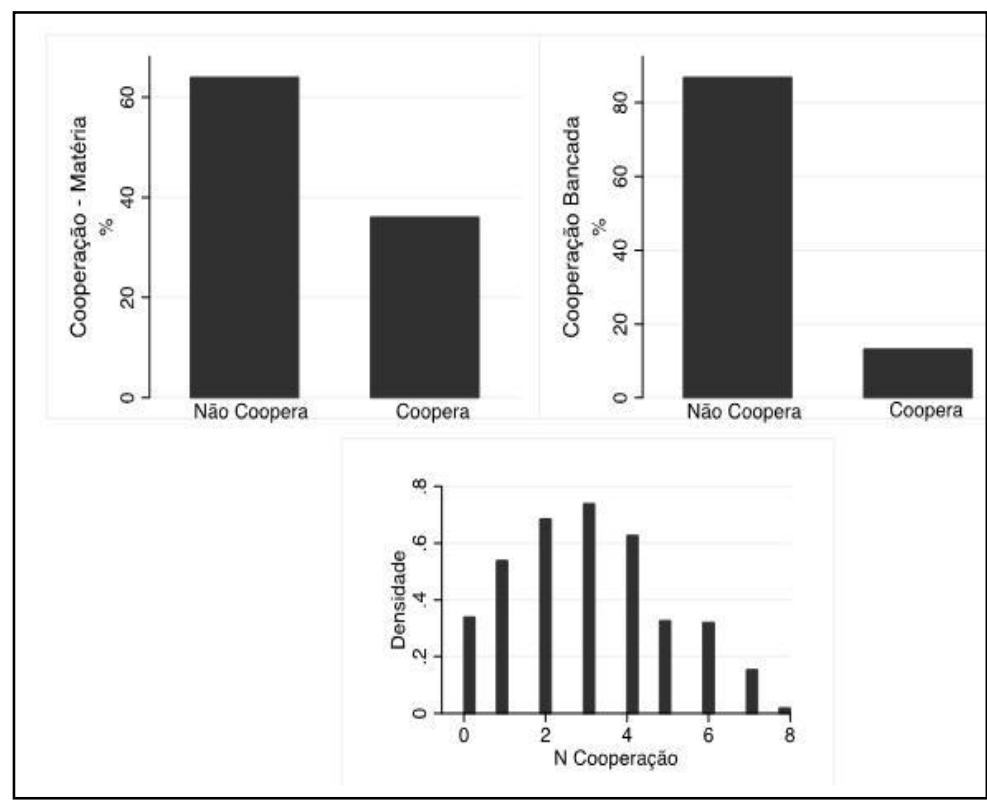

Fonte: Elaboração própria com base nos dados da Câmara dos Deputados.

O primeiro gráfico, no lado esquerdo, mostra que, considerando a votação dos parlamentares nas matérias analisadas, $64 \%$ não cooperam e 36\% cooperam com o setor. Quando considerada a participação no grupo que coopera mais fortemente, a bancada da indústria, $13 \%$ podem ser classificados como altamente cooperativos e $87 \%$ como não cooperativos. Por último, o terceiro gráfico mostra a distribuição do número de votos a favor dos interesses da indústria. Os valores variam entre 0 e 8 votos com a indústria no período de uma legislatura e o centro da distribuição está em 3 votos a favor. Mesmo apresentando estrutura de contagem, a distribuição aproxima-se da normal. A ausência de sobredispersão indica que o modelo de Poisson é o mais apropriado ${ }^{18}$. A Tabela 1 apresenta os resultados dos modelos de regressão:

\footnotetext{
18 A regressão de Poisson é usada em dados de contagem em que a média e a variância são iguais. Quando sobredispersão é identificada, o modelo binomial negativo deve ser usado. O Stata 12 apresenta o teste para sobredispersão juntamente com o modelo binomial negativo (LONG; FREESE, 2001).
} 
SANTOS, M. L. et al. Financiamento de campanha e apoio parlamentar à Agenda...

Tabela 1

Financiamento de campanha e comportamento parlamentar

\begin{tabular}{|c|c|c|c|c|c|c|c|}
\hline & \multicolumn{3}{|c|}{$\begin{array}{l}\text { Regressão logística } \\
\text { VD = Cooperação }\end{array}$} & \multicolumn{2}{|c|}{$\begin{array}{l}\text { Regressão logística } \\
\text { VD = Bancada }\end{array}$} & \multicolumn{2}{|c|}{$\begin{array}{c}\text { Poisson } \\
\text { VD }=\mathrm{N} \text { cooperação }\end{array}$} \\
\hline Variável & Modelo 1 & Modelo 2 & Modelo 3 & Modelo 4 & Modelo 5 & Modelo 6 & Modelo 7 \\
\hline Constante & $\begin{array}{l}0,001^{* * * *} \\
(0,219)\end{array}$ & $\begin{array}{l}0,000 * * * \\
(0,220)\end{array}$ & $\begin{array}{l}0,020 * * * \\
(0,128)\end{array}$ & $\begin{array}{c}0,020^{* * *} \\
(0,487)\end{array}$ & $\begin{array}{c}0,018^{* * *} \\
(0,496)\end{array}$ & $\begin{array}{c}-0,658 * * * \\
(0,103)\end{array}$ & $\begin{array}{c}-0,685^{* * *} \\
(0,105)\end{array}$ \\
\hline $\begin{array}{l}\text { Proporção } \\
\text { indústria }\end{array}$ & $\begin{array}{l}0,886 \\
(0,133)\end{array}$ & - & - & $\begin{array}{c}0,962 \\
(0,583)\end{array}$ & - & $\begin{array}{l}-0,055 \\
(0,068)\end{array}$ & - \\
\hline $\begin{array}{l}\text { Proporção } \\
\text { corporativo }\end{array}$ & - & $\begin{array}{l}1,307^{* * *} \\
(0,118)\end{array}$ & $\begin{array}{l}1,198 * * * \\
(0,081)\end{array}$ & - & $\begin{array}{c}1,488 \\
(0,292)\end{array}$ & - & $\begin{array}{l}0,117^{*} \\
(0,062)\end{array}$ \\
\hline Ideologia & $\begin{array}{l}1,603^{* * *} \\
(0,026)\end{array}$ & $\begin{array}{l}1,582^{* * * *} \\
(0,026)\end{array}$ & $\begin{array}{l}1,201^{* * *} \\
(0,017)\end{array}$ & $\begin{array}{c}1,807^{* * *} \\
(0,092)\end{array}$ & $\begin{array}{c}1,774^{* * *} \\
(0,094)\end{array}$ & $\begin{array}{l}0,118^{* * * *} \\
(0,012)\end{array}$ & $\begin{array}{l}0,112^{* * * *} \\
(0,012)\end{array}$ \\
\hline Background & $\begin{array}{l}1,393^{* * * *} \\
(0,163)\end{array}$ & $\begin{array}{l}1,358 * \\
(0,163)\end{array}$ & $\begin{array}{c}1,128 \\
(0,106)\end{array}$ & $\begin{array}{c}0,866 \\
(0,421)\end{array}$ & $\begin{array}{c}0,836 \\
(0,422)\end{array}$ & $\begin{array}{c}0,024 \\
(0,075)\end{array}$ & $\begin{array}{c}0,015 \\
(0,075)\end{array}$ \\
\hline $\begin{array}{l}\text { Origem } \\
\text { (Exec.) }\end{array}$ & $\begin{array}{l}6,282^{* * * *} \\
(0,123)\end{array}$ & $\begin{array}{l}6,244^{* * *} \\
(0,123)\end{array}$ & $\begin{array}{c}11,530 * * * \\
(0,085)\end{array}$ & - & - & - & - \\
\hline $\begin{array}{l}\text { Concordância } \\
\text { CNI/Exec. }\end{array}$ & $\begin{array}{c}86,692 * * * \\
(0,099)\end{array}$ & $\begin{array}{c}86,793^{* * *} \\
(0,099)\end{array}$ & - & - & - & - & - \\
\hline Disciplinado & $\begin{array}{l}0,086 * * * \\
(0,140)\end{array}$ & $\begin{array}{l}0,086^{* * *} \\
(0,140)\end{array}$ & $\begin{array}{l}0,264^{* * *} \\
(0,120)\end{array}$ & $\begin{array}{l}0,065^{* *} \\
(1,314)\end{array}$ & $\begin{array}{l}0,065^{* *} \\
(1,341)\end{array}$ & $\begin{array}{c}-0,869 * * * \\
(0,167)\end{array}$ & $\begin{array}{c}-0,870^{* * *} \\
\quad(.167)\end{array}$ \\
\hline Legislatura 52 & $\begin{array}{c}2,777^{* * * *} \\
(0,103)\end{array}$ & $\begin{array}{l}2,303^{* * *} \\
(0,114)\end{array}$ & $\begin{array}{c}3,675^{* * *} \\
(0,079)\end{array}$ & $\begin{array}{c}0,005^{* * *} \\
(1,032)\end{array}$ & $\begin{array}{c}0,004^{* * *} \\
(1,020)\end{array}$ & $\begin{array}{l}0,287^{* * * *} \\
(0,054)\end{array}$ & $\begin{array}{l}0,209 * * * \\
(0,059)\end{array}$ \\
\hline $\mathrm{N}^{\circ}$ de votos & - & - & - & - & - & $\begin{array}{l}0,124^{* * * *} \\
(0,006)\end{array}$ & $\begin{array}{l}0,123^{* * * *} \\
(0,006)\end{array}$ \\
\hline LogLikelihood & 5192,72 & 5188,39 & 9299,59 & 55,85 & 554,00 & $-1.680,17$ & $-1.678,72$ \\
\hline LRChi $^{2}$ & - & - & - & - & - & $567,76^{* * *}$ & $570,67^{* * *}$ \\
\hline $\begin{array}{c}\text { Pseudo } \mathrm{R}^{2} \text { Cox } \\
\text { e Snell }\end{array}$ & 0,488 & 0,488 & 0,146 & 0,211 & 0,212 & - & - \\
\hline $\begin{array}{l}\text { Pseudo } \mathrm{R}^{2} \\
\text { Nagelkerke }\end{array}$ & 0,667 & 0,667 & 0,199 & 0,378 & 0,381 & - & - \\
\hline$\%$ Predito & 86,8 & 88,0 & 68,8 & 85,0 & 85,2 & - & - \\
\hline Pseudo $\mathrm{R}^{2}$ & - & - & - & - & - & 0,144 & 0,145 \\
\hline $\mathrm{N}^{1}$ & 8.037 & 8.037 & 8.037 & 960 & 960 & 960 & 960 \\
\hline
\end{tabular}

Fonte: Santos (2011)

Modelo Logit: $\exp (b)$ reportado, erro-padrão entre parênteses.

Modelo Poisson: coeficiente reportado, erro-padrão entre parênteses.

*** significância $P<0,01$; ** significância $P<0,05$; significância *P $<0,10$

${ }^{1}$ Conforme o Quadro 1, no total foram 9.903 votos em plenário e 1.171 parlamentares incluídos na análise. Os números ligeiramente inferiores constantes nos modelos de regressão se devem à falta de informações sobre o financiamento de campanha de alguns parlamentares.

19 Como a proporção de fracassos (0) é muito maior do que a proporção de sucessos (1), como visto no Gráfico 1 , o modelo de regressão logística pode ser problemático uma vez que superestima o fracasso e subestima o sucesso (KING; ZENG, 2001). Para identificar se esse problema existe em nossas estimativas, um modelo de regressão logística para eventos raros foi estimado. Contudo, os resultados apresentados foram os mesmos do modelo clássico aqui reportado. 
A proporção de recursos de campanha do parlamentar oriunda de contribuições da indústria (proporção indústria) não foi estatisticamente significativa em nenhum dos modelos. Embora o sentido da relação esperada tenha se confirmado como positivo nos modelos 1 e 4 (regressões logísticas), a variável apresentou sinal contrário ao esperado teoricamente ( $\beta=-)$ no modelo 6 (de Poisson). Nesse sentido, o resultado aqui encontrado está mais próximo da minoria (os 23,7\% citados anteriormente) dos estudos que não identificam efeito do financiamento de campanha sobre o comportamento parlamentar ${ }^{20}$. 0 resultado, portanto, frustra a expectativa inicial.

O resultado, contudo, deve ser visto com cautela. É possível que esse resultado contraintuitivo seja decorrente da presença de erros de mensuração sistemáticos ${ }^{21}$ e aleatórios ${ }^{22}$ da variável independente, que são impossíveis de corrigir. O erro de mensuração sistemático sempre causa viés em estudos descritivos, seja sobre-estimando seja subestimando o valor do parâmetro populacional. Por outro lado, ele não gera viés nas estimativas do modelo de regressão. Por sua vez, o erro aleatório não produz viés em estudos descritivos porque erros grandes são cancelados por erros pequenos. Logo, em média, tem-se uma aproximação não viesada do parâmetro populacional. Em estudos de causa e efeito, a presença de erro aleatório causa ineficiência, mas não há viés quando o erro é na variável dependente. Por fim, quando o erro é na variável independente tem-se o pior cenário: viés e ineficiência das estimativas ${ }^{23}$. Ainda no que diz respeito ao erro aleatório, é importante identificar onde ele ocorre. Quando o erro é na mensuração da variável dependente, ocorrem problemas de ineficiência, mas as estimativas não são viesadas. Por outro lado, quando o erro de mensuração é na variável independente, ocorrem problemas de ineficiência e viés nas estimativas. Para Gerber (1994), "using an independent variable that is measured with random error will certainly bias the estimated coefficients in a multiple linear regression and may even reverse the signs of the coefficients" (GERBER, 1994, p. 1.107). King, Keohane e Verba (1994) afirmam que existe uma tendência a subestimar o efeito da variável independente sobre a variável dependente.

Em relação ao erro sistemático, é conhecida a tendência ao sub-registro das contribuições de campanha, mesmo não sendo esta de fato mensurada. Na medida em que todos os deputados têm, em média, o mesmo incentivo para subestimar a quantidade de recursos recebidos, tem-se erro sistemático de mensuração na variável independente. Estima-se que parte considerável dos recursos de campanha pode ser feita pela via do caixa 2. Para piorar, é possível que tenhamos erros aleatórios na mensuração da variável independente. No caso de contribuições corporativas, a classificação é feita simplesmente pela existência de

\footnotetext{
20 Para os estudos que não encontraram relação estatisticamente significativa entre contribuições de campanha e apoio parlamentar, ver Kau e Rubin (1978); Welch (1982); Chappell (1982); Wright (1985); Grenzke (1989); Dow e Endersby (1994); Bronars e Lott (1997) e Wawro (2001).

${ }^{21} \mathrm{O}$ erro sistemático ocorre quando existe algum padrão de erro na mensuração das variáveis dependentes e/ou independentes. Um exemplo típico desse tipo de erro ocorre em pesquisas de survey quando os respondentes têm incentivos para subestimar ou superestimar um padrão de resposta. Em uma pesquisa sobre comportamento sexual, o erro sistemático poderia ocorrer se existisse a tendência de homens superestimarem a quantidade de parceiras e as mulheres subestimarem o número de parceiros. Em trabalhos descritivos, erros sistemáticos de mensuração sempre produzem resultados viesados (KING; KEOHANE; VERBA, 1994).

22 Tecnicamente, o erro aleatório na variável dependente é absorvido pelo termo de erro da equação de regressão, aumentando a sua variância. Um dos efeitos disso é a subestimação do coeficiente de determinação $\left(r^{2}\right)$. Ou seja, quando a variável dependente é mensurada com erro aleatório, espera-se que a quantidade de variância explicada pelo modelo seja menor do que quando a variável dependente é medida sem erro. As estimativas serão menos eficientes (maior variância), mas continuarão sendo não viesadas.

${ }^{23}$ A preocupação em garantir medidas válidas e confiáveis deve ocorrer antes de estimar o modelo. Depois de estimar os coeficientes é impossível avaliar se a presença de erros de mensuração afetou as estimativas. Para os interessados no assunto, ver Carmines e Zeller (1979) e Sullivan e Feldman (1979).
} 
SANTOS, M. L. et al. Financiamento de campanha e apoio parlamentar à Agenda...

um CNPJ. No caso da contribuição pela indústria, é preciso identificar os ramos de atuação da empresa. Dessa forma, a classificação se torna mais subjetiva e sujeita a erro. O principal efeito do erro aleatório é a ineficiência e o viés nas estimativas.

Como dito acima, a variável financiamento de campanha foi operacionalizada de duas formas, na intenção de explorar possíveis hipóteses sobre os mecanismos de financiamento de campanha no Brasil e suas relações com o comportamento legislativo. Fenômeno desconhecido e ausente na literatura especializada. A segunda especificação da variável independente é a proporção de recursos corporativos recebidos pelo candidato (proporção corporativo). Essa nova variável ainda sofre com problemas de erro sistemático, mas não de erro aleatório. Logo, as estimativas produzidas não são viesadas ${ }^{24}$. Os resultados indicam que, controlando pelas demais variáveis, a proporção de recursos corporativos tem efeito positivo e estatisticamente significativo sobre a probabilidade de cooperação (modelos 2 e 3). No modelo 2, cada ponto percentual adicional do financiamento corporativo no total arrecadado pelo candidato resulta em 30,7\% mais de chance de o deputado votar a favor da indústria. Já no modelo 3 , cada ponto percentual resulta em 19,8\% mais de chance de o deputado cooperar com o setor. No modelo Poisson, o efeito também é positivo e estatisticamente significativo $(\beta=0,117$; erro-padrão $=0,062$ ) (modelo 7). Por fim, no modelo logístico da bancada, o efeito da proporção de recursos corporativos novamente foi positivo, mas não significativo ( $\operatorname{Exp} \beta=1,488$; erro-padrão $=0,292$ ) (modelo 5). Em conjunto, esses resultados sugerem que, mantendo diferentes variáveis constantes, a proporção de recursos corporativos influencia positivamente a cooperação dos parlamentares brasileiros com os interesses da CNI. Em suma, é possível afirmar que o dinheiro que vem das empresas influencia o apoio dos parlamentares à Agenda Legislativa da Indústria.

Assim, embora de certa forma controversos, esses achados inéditos iniciam uma tentativa de superar a lacuna na literatura nacional sobre comportamento parlamentar e devem ser colocados em testes tomando como referência outras legislaturas e interesses.

No que diz respeito às demais variáveis independentes, o resultado foi, em parte, o esperado. A ideologia, em todos os modelos, mostrou efeito positivo e estatisticamente significativo. Ou seja, quanto mais à direita no espectro ideológico, maior é a cooperação com os interesses da CNI. O maior efeito encontrado foi no modelo 4 , que indica que a cada ponto mais à direita na escala de ideologia, que vai de 1 a 10 , a chance de o deputado cooperar aumenta $80,7 \%$. Esse resultado encontra reforço se pensado conjuntamente com os achados de Santos (2011), que, no seu estudo sobre o efeito do lobby no comportamento legislativo, demonstrou que a ideologia importa nas votações nominais relativas à Agenda Legislativa da Indústria na Câmara dos Deputados.

Já no que diz respeito ao background do parlamentar, os resultados são menos conclusivos. Esse background mostrou-se relevante apenas nos modelos 1 e 2 (regressão logística). No modelo 1, ser um deputado empresário da indústria aumenta em 39,3\% a chance de ele cooperar com o setor. No modelo 2 ,

${ }^{24}$ Nas palavras de King, Keohane e Verba, "systematic measurement error which affects all units by the same constant amount causes no bias in causal inference" (KING; KEOHANE; VERBA, 1994, p. 156). 
essa chance diminui para 35,8\%. Muito embora não devamos ignorar que o sentido da relação foi o esperado em todos os modelos $(\beta=+)$.

No que diz respeito às variáveis de controle, os resultados são os esperados. A literatura de ciência política no Brasil afirma que o Poder Executivo conta com poderes de agenda suficientes para aprovar sua agenda legislativa (FIGUEIREDO; LIMONGI, 2001; INÁCIO, 2006) e que a disciplina partidária é mais alta do que em geral o senso comum defende (SILVA JUNIOR, 2008). Se considerarmos especialmente as duas variáveis que controlam a participação do Poder Executivo no processo decisório (origem do Executivo e concordância da CN/ com o Executivo), o que se vê é que elas são estatisticamente significativas para os modelos 1,2 e 3. Ou seja, os deputados cooperam mais com o interesse da indústria quando o projeto é de autoria do Executivo e quando o governo e o setor industrial estão alinhados sobre a proposição. Especial atenção deve ser dada à magnitude dos efeitos dessas variáveis de controle sobre a variável dependente. Poder-se-ia argumentar, mas sem razão, que a magnitude dos efeitos das variáveis de controle é mais expressiva do que a dos efeitos das variáveis independentes e, portanto, que o modelo estaria mal especificado. Defendemos aqui uma posição oposta. Defendemos que nossos achados, baseados nas variáveis independentes aqui elencadas, têm relevância exatamente porque se mantêm mesmo controlando por essas variáveis "consagradas" pela literatura, ainda que os erros sistemáticos e aleatórios anteriormente citados comprometam sobremaneira sua estimação exata.

Em nosso favor temos, ainda, que tecnicamente as estatísticas de ajuste dos modelos sugerem Pseudo $\mathrm{R}^{2}$ Cox e Snell de 0,488 e Pseudo $\mathrm{R}^{2}$ Nagelkerke de 0,667, que estão muito acima dos indicadores de ajuste usualmente reportados em modelos de ciência política. Em particular, o modelo 2 apresentou percentual de predição correta geral de $88 \%$.

Para facilitar a interpretação substantiva dos resultados, optamos por reportar graficamente a magnitude do efeito da variável de interesse nos diferentes modelos. 0 Gráfico 2 ilustra as informações ${ }^{25}$ :

\footnotetext{
${ }^{25}$ Estimações obtidas com o comando "margins" e gráficos com o comando "marginsplot" do Stata 12.
} 
Gráfico 2

Efeito do financiamento de campanha sobre o comportamento parlamentar

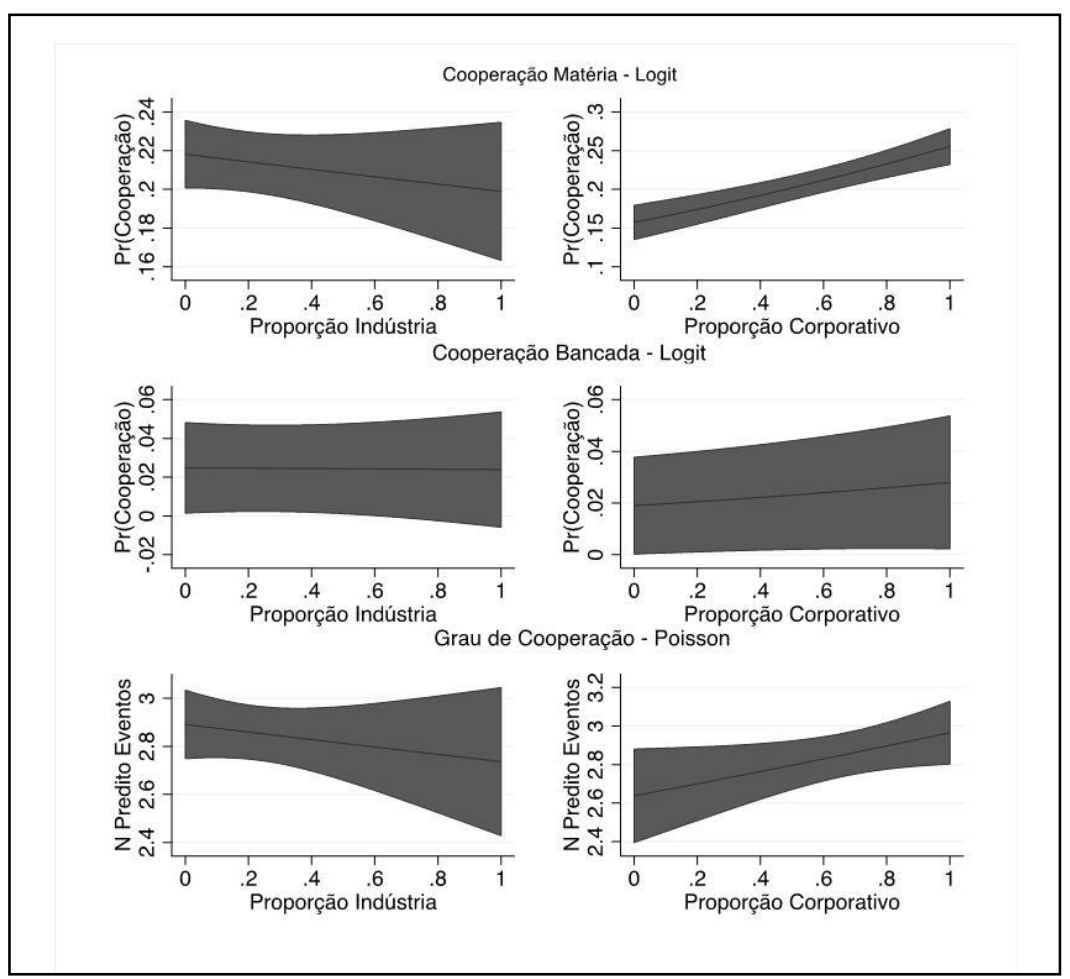

Fonte: Elaboração própria com base em dados da Câmara dos Deputados e Samuels (2001a).

O painel esquerdo apresenta o efeito da variável proporção de financiamento da indústria com erros sistemáticos e aleatórios de mensuração, e os resultados não são diferentes de zero. No painel direito podemos ver o efeito da proporção de financiamento corporativo sobre o comportamento parlamentar. A tendência é positiva, independentemente do tipo de especificação da variável dependente. Sob nenhuma hipótese estamos defendendo que o financiamento de campanha é o único, nem o mais relevante, preditor do comportamento parlamentar no Brasil. Mas os resultados nos deixam confiantes de que este artigo identificou mais um fator explicativo para o comportamento dos deputados federais: o tipo de financiamento de campanha que recebem.

\section{Conclusão}

A hipótese sobre a influência do financiamento específico da indústria sobre o comportamento parlamentar em matérias de interesse do setor não se confirmou, mas muitos resultados substantivos foram reportados. O principal deles é que a proporção de recursos corporativos influencia positivamente a 
cooperação dos parlamentares brasileiros com os interesses legislativos da CNI. O dinheiro vindo dos empresários para as campanhas dos deputados federais no Brasil importa para explicar como eles se comportam nas votações nominais no parlamento. Em suma, quanto maior a proporção de recursos vindos de empresas, maior é a cooperação dos deputados em matérias de interesse do setor produtivo.

Outro resultado relevante é a força da ideologia como preditor do comportamento parlamentar. 0 resultado confirma achado semelhante de Santos (2011) quando estudou a força do lobby da indústria no parlamento. Ademais, esse achado soma o fator ideologia aos determinantes do comportamento legislativo comumente tratados pela literatura nacional, baseados na ideia de que o parlamentar age sob o constrangimento do Poder de Agenda do Presidente (FIGUEIREDO; LIMONGI, 2001; INÁCIO, 2006) e que a disciplina partidária é mais alta do que em geral se espera (SILVA JUNIOR, 2008). Nesse sentido, o comportamento parlamentar no Brasil ganha fatores explicativos complementares.

Por outro lado, o achado se alinha parcialmente com a literatura internacional que sustenta que a influência do financiamento se dá "em geral numa questão não partidária e não ideológica"26. Sabe-se, contudo, que muitas outras condições são sustentadas como relevantes pela literatura internacional. Isso leva a crer que a inclusão de mais uma peça é um passo importante, mas o quebra-cabeça mais amplo sobre comportamento parlamentar no Brasil ainda está por ser montado.

Outro achado interessante, mas de menor relevância e um pouco mais controverso, diz respeito ao background do parlamentar. Ser um deputado empresário da indústria se mostrou relevante para o apoio ao setor em alguns modelos testados, mas não em todos. Esse achado sugere que o financiamento de campanha pode ser visto como um mecanismo de reforço ou, ainda, um indicador de autofinanciamento, já que no Brasil o deputado é responsável pela arrecadação dos recursos para a própria campanha. Essas interpretações, entretanto, carecem de maiores investigações sobre o padrão de financiamento de campanha e sobre os mecanismos relacionados aos efeitos desse financiamento sobre o comportamento parlamentar entre os membros do próprio grupo.

Metodologicamente, é necessário destacar o esforço de Samuels (2001c) em elaborar o primeiro banco de dados capaz de desagregar as fontes de financiamento político no Brasil. Mais importante, temos que registrar a sua iniciativa em compartilhar a base de dados, o que permite não só a replicabilidade dos seus resultados, mas também favorece que outros estudos sejam realizados utilizando a mesma base de dados. O mesmo pode ser dito em relação aos dados de Power e Zucco (2009), Santos (2011), e aos dados cedidos por Fabiano Santos (lesp-Uerj) e Renato Boschi (lesp-Uerj). Fundamentalmente, este artigo só foi possível porque esses pesquisadores compartilharam seus dados, tendo como objetivo coletivo o aprimoramento do conhecimento científico.

Blalock (1974) afirmou que um dos principais obstáculos ao avanço da ciência são os problemas de conceitualização e mensuração. Em particular, esses problemas são especialmente presentes nas ciências humanas que geralmente mensuram conceitos não diretamente observáveis e convivem com fontes limitadas de dados. Ou seja, uma mistura potencialmente desastrosa pela quantidade de erros sistemáticos e/ou aleatórios que podem contaminar as medidas de interesse. Nosso artigo demonstrou que variáveis mal

${ }^{26}$ Ver Conway (1991); Frendreis e Waterman (1985); Magleby e Nelson (1990); Malbin (1984); Mutch (1988); Schlozman e Tierney (1986); Welch (1982) e Wright (1985). 
medidas reduzem a consistência das estimativas e comprometem a interpretação substantiva dos resultados. Mas isso não quer dizer que devemos, como se diz coloquialmente, "jogar fora o bebê com a água do banho". Pelo contrário, é importante que os pesquisadores reportem de forma exata e transparente as suas dificuldades metodológicas de mensuração para que outros pesquisadores possam aprender com elas, contribuir com essa mensuração e aprimorá-la. Afinal, medidas confiáveis e válidas constituem um elemento fundamental na construção do conhecimento científico. Esperamos com este artigo colaborar com a literatura sobre financiamento de campanha e comportamento parlamentar e em especial suscitar o debate sobre novas formas de observação e mensuração desses conceitos.

\section{Referências Bibliográficas}

ABLER, D. "Campaign contributions and house voting on sugar and dairy legislation". American Journal of Agricultural Economics, vol. 73, p. 11.17, 1991.

Aldenderfer, M. S.; Blashfield, R. K. Cluster analysis. Sage University Paper Series: Quantitative Applications in the Social Science, 1984.

BAIELY, K. D. "Cluster analysis". Sociological Methodology, vol. 6, p. 59-128, 1975.

BLALOCK, H. M. Measurement in the social sciences: theories and strategies. Chicago: Aldine, 1974.

BRONARS, S.; LOTT, J. JR. "Do campaign donations alter how a politician votes? Or, do donors support candidates who value the same things that they do?". Journal of Law and Economics, vol. 40, n² 2, p. 317-350, 1997.

Buchanan, J.; TULlock, G. The calculus of consent. Ann Arbor: University of Michigan, 1962.

Carmines, E. G.; Zeller, R. A. Reliability and validity assessment. Quantitative Applications in the Social Sciences Series. Beverly Hills: Sage Publications, 1979.

Cervi, E. U. "Instituições democráticas e financiamento de campanhas no Brasil: análises das contribuições de pessoas físicas, jurídicas e partidos políticos às eleições de 2008 e o financiamento público exclusivo de campanha". In: Anais do $33^{\circ}$ Encontro Anual da Associação Nacional de Pós-Graduação em Ciências Sociais. Caxambu, MG, p. 1·30, 2009.

CHAPPELL, H. W. "Campaign contributions and voting on the cargo preference bill: a comparison of simultaneous models". Public Choice, vol. 36, p. 301-312, 1981.

"Campaign contributions and congressional voting: a simultaneous probit-tobit model". Review of Economics and Statistics, vol. 61, p. $77.83,1982$.

CHOATE, P. Agents of influence: how Japan's lobbyists in the United States manipulate America's political and economic system. New York: Alfred A. Knopf, 1990.

CLawson, D. Dollars and votes: how business campaign contributions subvert democracy. Philadelphia: Temple University Press, 1999.

Conway, M. M. PACs in the political process. In: CIGLER, A. J.; LOOMIS, B. A. (eds.). Interest group politics. $3^{\text {a }}$ ed. Washington, DC: Congressional Quarterly Press, 1991.

CoRRADO, A., et al. The new campaign finance sourcebook. Washington: Brookings Institution Press, 2005.

Coughlin, P.J. "Domestic content legislation: house voting and the economic theory of regulation". Economic Inquiry, vol. 23, p. $437.448,1985$ 
DAVIS, F. L. "Balancing the perspectives on PAC contributions: in search of an impact on roll calls". American Politics Quarterly, vol. 21, 1993.

Denzau, A.; Munger, M. "Legislators and interest groups: how unorganized interest get represented". American Political Science Review, vol. 80, p. 89.106, 1986.

Dow, J. K.; Endersby, J. W. "Campaign contributions and legislative voting in the California Assembly". American Politics Quarterly, vol. 22, 1994.

Driver, H. E.; Kroeber, A. L. Quantitative expressions of cultural relationships. Berkeley: University of California Press, 1932.

Durden, G. C.; Shogren, J. S.; Silberman, J. L. "The effect of interest group pressure on coal strip-mining legislation". Social Science Quarterly, vol. 72, p. 239.250, 1991.

Evans, D. PAC contributions and roll-call voting: conditional power. In: CIGLER, A. J.; LOOMIS, B. A. (eds.). Interest group politics. $3^{\mathrm{a}}$ ed. Washington, DC: Congressional Quarterly Press, 1986.

FeldSteIn, P. J.; MeLniCK, G. "Congressional voting behavior on hospital legislation: an exploratory study". Journal of Health Politics, Policy and Law, vol. 8, n 4, 1984.

FigueIREDO FILHO, D. B. "O elo corporativo? Grupos de interesses, financiamento de campanha e regulação eleitoral". Dissertação de Mestrado em Ciência Política. Universidade Federal de Pernambuco, Recife, 2009.

Figueiredo Filho, D. B.; Silva Junior, J. A.; Rocha, E. C. "Classificando regimes políticos utilizando análise de conglomerados". Opinião Pública, Campinas, vol. 18, nº 1, 2012.

FigueIREdo, A.; LIMOnGI, F. Executivo e Legislativo na nova ordem constitucional. Rio de Janeiro: Editora FGV, 2001.

FLEISHER, R. "PAC contribution and congressional voting on national defense". Legislative Studies Quarterly, vol. 18, p. 391 . 409, 1993.

FRENDREIS, J. P.; WATERMAN, R. W. "PAC contributions and legislative behavior: Senate voting on trucking deregulation". Social Science Quarterly, vol. 66, p. 401.412, 1985.

GERBER, A. "The mismeasure of campaign spending: evidence from the 1990 U.S. House elections". Journal of Politics, November, 1994.

GodwIN, K. One billion dollars of influence: the direct marketing of politics. Chatham: Chatham House, 1988.

GRENZKE, J. M. "PACs and the congressional supermarket: the currency is complex". American Journal of Political Science, vol. 33, p. 1.24, 1989.

Grier, K. B.; MUnGer, M. C. "Comparing interest group PAC contributions to House and Senate incumbents, 1980-1986". The Journal of Politics, vol. 55, n 3, p. 615.643, 1993.

HaLL, R. L.; Wayman, F. W. "Buying time: moneyed interests and the mobilization of bias in congressional committees". American Political Science Review, vol. 84, p. 797-820, 1990.

Hersch, P. L.; McDougall, G. S. "Voting for 'Sin' in Kansas”. Public Choice, vol. 57, n² 2, 1988.

Holian, D. B.; Krebs, T. B. "Constituency opinion, Ross Perot, and Roll-Call Behavior in the U.S. House: The Case of the Nafta”. Legislative Studies Quarterly, vol. 22, 1997.

InÁCIO, M. Os poderes de agenda do presidente. In: AnASTAsIA, F.; AvRITZer, L. (orgs.). Reforma política no Brasil. $1^{\text {a }}$ ed. Belo Horizonte: Editora UFMG, p. 170-174, 2006.

JoHnson, L. L. "The effectiveness of savings and loan political action committees". Public Choice, vol. 46, n 3, 1985.

Jones, W.; KAISER, K. R. "Issue visibility and the effects of PAC money". Social Science Quarterly, vol. 68, p. 170-176, 1987.

Kau, J. B.; Rubin, P. H. "Voting on minimum wages: a time-series analysis". Journal of Political Economy, vol. 86, p. 337. 342,1978 
KING, G. "The future of replication". International Studies Perspectives, vol. 4, p. 443-499, 1995. Disponível em: <http://gking.harvard.edu/gking/files/replvdc.pdf>.

King, G.; Keohane, R; Verba, S. Designing social inquiry. New Jersey: Princeton University Press, 1994.

KInG, G.; Zeng, L. "Logistic regression in rare events data”. Political Analysis, vol. 9, p. 137-163, 2001.

LANDES, W. M.; Posner, R. A. "The independent Judiciary in an interest-group perspective". Journal of Law and Economics, University of Chicago Press, vol. 18, n³, p. 875-901, 1975.

LANGBEIN, L. "Money and access: some empirical evidence". The Journal of Politics, vol. 48, n 4, p. 1.052-1.062, 1986. "PACs, lobbies, and political conflict: the case of gun control". Public Choice, vol. 77, p. 551-572, 1993.

LANGBEIN, L.; LOTWIS, M. "The political efficacy of lobbying and money: gun control in the U.S. House, 1986". Legislative Studies Quarterly, vol. 15, 1990.

Lemos, L. B.; Marcelino, D.; Pederiva, J. H. "Por que dinheiro importa: a dinâmica das contribuições eleitorais para o Congresso Nacional em 2002 e 2006". Opinião Pública [online]. vol. 16, n² 2, p. 366-393, 2010.

Long, J. S.; FREESE, J. Regression models for categorical dependent variables. College Station, TX: Stata Press, 2001.

Magleby, D. B.; Nelson, C. J. The money chase: congressional campaign finance reform. Washington, D.C.: Brookings, 1990.

MALBIN, M. J. Money and politics in the United States: financing elections in the 1980s. American Enterprise Institute for Public Policy Research, 1984.

Mancuso, W. P. O lobby da indústria no Congresso Nacional: empresariado e política no Brasil contemporâneo. São Paulo: Edusp/Humanitas, 2007.

MASTERS, M. F.; ZARDKOOHI, A. "Congressional support for unions: positions across diverse legislation". Journal of Labor Research, vol. 9, p. 149.165, 1988.

MCChesney, F. Money for nothing: politicians, rent extraction, and political extortion. Cambridge: Harvard University Press, 1997.

Mutch, R. Campaigns, Congress, and courts. The making of federal campaign finance law. New York: Praeger, 1988.

NeUSTADTL, A. "Interest group PACsmanship: an analysis of campaign contributions, issue visibility and legislative impact". Social Forces, vol. 69, n² 1990.

OLson, M. The logic of collective action. Cambridge: Harvard University Press, 1965.

PEIхото, V. "Votos: valem quanto pesam? O impacto do financiamento de campanhas eleitorais no Brasil". Dissertação de Mestrado em Ciência Política do Instituto Universitário de Pesquisas do Rio de Janeiro, 2004. MG, 2008. Impacto dos gastos de campanhas nos resultados eleitorais. In: Anais do $32^{\circ}$ Encontro Anual da Anpocs, Caxambu

"Financiamento de campanhas nas eleições legislativas brasileiras em 2010". Em Debate, Belo Horizonte, vol. 6 , p. 36.54, 2014.

PeLtZMAN, S. "Towards a more general theory of regulation". Journal of Law and Economics, vol. 19, p. 211-240, 1976.

"Constituent interest and congressional voting". Journal of Law and Economics, vol. 27, p. 181·210, 1984.

Pincus, J. J. "Pressure groups and the pattern of tariffs". Journal of Political Economy, vol. 83, p. 757-777, 1975.

Portugal, A. C.; Bugarin, M. "Financiamento público e privado de campanhas eleitorais: efeitos sobre bem-estar social e representação partidária no legislativo". Revista de Economia Aplicada, Ribeirão Preto-SP, vol. 7, n 3, p. 549.584, 2003. 
POSNER, R. "The social cost of monopoly and regulation". Journal of Political Economy, vol. 83, p. 807-27, 1975.

Power, T.; Zucco, C. "Estimating ideology of Brazilian Legislative parties, 1990-2005: a research communication". Latin American Research Review, vol. 44, nº 1, p. 218-246, 2009.

SABATO, L. PAC power: inside the world of political action committees. New York: W.W. Norton, 1985.

Saltzman, G. M. "Congressional voting on labor issues: the role of PACs". Industrial and Labor Relations Review, vol. 40, p. 163.179, 1987.

SAmUELS, D. "Does money matter? Campaign finance in newly democratic countries: theory and evidence from Brazil". Comparative Politics, vol. 34, p. 23.42, 2001a.

Incumbents and challengers on a level playing field: assessing the impact of campaign finance in Brazil. The Journal of Politics, vol. 63, n² 2, p. 569.84, 2001 b.

"Money, elections and democracy in Brazil". Latin American Politics and Society, vol. 43, n 7, p. 27.48, 2001c.

Financiamento de campanha e eleições no Brasil: o que podemos aprender com o "caixa um" e propostas de reforma. In: Benevides, M. V., et al. (orgs.). Reforma política e cidadania. São Paulo: Editora Fundação Perseu Abramo, 2003.

Financiamento de campanhas no Brasil e propostas de reforma. In: SOARES, G. A. D.; RenNo, L. R. Reforma política: lições da história recente. Rio de Janeiro: Editora FGV, 2006.

Santos, M. L. "O parlamento sob influência: o lobby da indústria na Câmara dos Deputados". Tese de Doutorado em Ciência Política. Universidade Federal de Pernambuco, 2011.

Schlozman, K.; Tierney, J. Organized interests in American democracy. New York: Harper and Row, 1986.

Schroedel, J. R. "Campaign contributions and legislative outcomes". Western Political Quarterly, vol. 39, p. 371.389, 1986

SHAVELL, S. "An economic analysis of threats and their illegality: blackmail, extortion, and robbery". University of Pennsylvania Law Review, vol. 141, p. 1.877-1.902, 1993.

Silberman, J.; DuRden, G. C. "Determining legislative preferences on the minimum wage: an economic approach". Journal of Political Economy, vol. 84, p. 317-329, 1976.

SILVA JUNIOR, J. A. "As sementes da discórdia: regras e exceções da indisciplina partidária". Dissertação de Mestrado em Ciência Política. Universidade Federal de Pernambuco, 2008.

SMITH, R. "Interest group influence in the U.S. Congress". Legislative Studies Quarterly, vol. 20, n 1, p. 89-139, 1995.

Sokal, R. R.; Sneath, P. H. A. Principles of numerical taxonomy. San Francisco: W. H. Freeman, 1963.

StIGLER, G. "The theory of economic regulation". Bell Journal of Economics and Management Science, vol. 2, p. 3.21, 1971.

Stratmann, T. "What do campaign contributions buy? Deciphering the causal effects of money and votes". Southern Economic Journal, vol. 100, p. 647.664, 1991.

"Campaign contributions and congressional voting: does the timing of contributions matter?". Review of Economics and Statistics, vol. 77, n 1, p. 127-136, 1995.

"The market for congressional votes: is timing of contributions everything?". Journal of Law and Economics, vol. $\overline{41, n^{\circ} 1}$, p. $85 \cdot 114,1998$.

"Can special interests buy congressional votes? Evidence from financial services legislation". Journal of Law and Economics, vol. 45, n², p. 345-374, 2002.

Sullivan, J. L.; Feldman, S. Multiple indicators: an introduction. Quantitative applications in the Social Sciences Series. Beverly Hills: Sage Publications, 1979. 
TOSINI, S. C.; TOWER, E. "The textile bill of 1985: the determinants of congressional voting patterns". Public Choice, vol. 54, p. 19.25, 1987.

TRYon, R. Cluster analysis. New York: McGrawHill, 1939.

TULLOCK, G. "The welfare costs of tariffs, monopolies, and theft". Western Economic Journal, vol. 5, p. 224-232, 1967.

WAWRO, G. "A panel probit analysis of campaign contributions and roll call votes". American Journal of Political Science, vol. 45, p. 563.579, 2001.

WELCH, W. P. "Campaign contributions and legislative voting: milk money and dairy price supports". Western Political Quarterly, vol. 35, p. 478.495, 1982.

WILHITE, A. "Union PAC contributions and legislative voting." Journal of Labor Research, vol. 9, p. 79.90, 1988.

WILHITE, A.; PAUL, C. "Corporate campaign contributions and legislative voting". Quarterly Review of Economics and Business, vol. 29, p. 73.86, 1989.

Wilhite, A.; TheiLmAnN, J. "Unions, corporations, and political campaign contributions: the 1982 House elections". Journal of Labor Research, vol. 7, p. 175-185, 1986.

\section{7.}

"Labor PAC contributions and labor legislation: a simultaneous logit approach". Public Choice, vol. 53, p. 267-276,

WRIGHT, J. R. "Contribution and roll calls: an organizational perspective". American Journal of Political Science Review, vol. 79, p. 400-414, 1985.

"Contributions, lobbying, and committee voting in the U.S. House of Representatives". American Political Science Review, vol. 84, p. 417.438, 1990. 
Anexo 1

\begin{tabular}{|c|c|c|c|c|}
\hline \multicolumn{5}{|c|}{ Descrição das matérias analisadas } \\
\hline Matéria & Posição da CNI & Resultado & Origem & Legislatura \\
\hline MPV $\cdot 0107 \cdot 2003$ & Divergente & Aprovado & Executivo & 52 \\
\hline PEC $\cdot 0040 \cdot 2003$ & Convergente com ressalvas & Aprovado & Executivo & 52 \\
\hline PEC $\cdot 0227 \cdot 2004$ & Divergente & Aprovado & Legislativo & 52 \\
\hline PEC - 0407.2001 & Divergente com ressalvas & Aprovado & Executivo & 51 \\
\hline PL · 1617-1999 & Convergente & Aprovado & Executivo & 51 \\
\hline$P L \cdot 2401 \cdot 2003$ & Divergente com ressalvas & Aprovado & Executivo & 52 \\
\hline PL · 3115-1997 & Convergente com ressalvas & Aprovado & Legislativo & 51 \\
\hline PLP $\cdot 0001 \cdot 1991$ & Convergente com ressalvas & Aprovado & Legislativo & 51 \\
\hline PLP - 0010.1999 & Convergente & Aprovado & Executivo & 51 \\
\hline PLP $\cdot 0072 \cdot 2003$ & Convergente & Aprovado & Legislativo & 52 \\
\hline PLP - 0077.1999 & Divergente & Aprovado & Executivo & 51 \\
\hline PLP - 0114-2000 & Divergente & Rejeitado & Executivo & 51 \\
\hline PLP - 0195.2001 & Divergente & Aprovado & Executivo & 51 \\
\hline
\end{tabular}

A escolha das matérias obedeceu a quatro critérios: 1) a matéria constar na Agenda Legislativa da Indústria da CNI; 2) a matéria ser objeto de votação nominal; 3) ser possível reconhecer a posição do setor naquela matéria; 4) disponibilidade de dados quanto ao financiamento de campanha, background, ideologia e demais variáveis de controle. 
SANTOS, M. L. et al. Financiamento de campanha e apoio parlamentar à Agenda...

Anexo 2

Apresentação da análise de cluster

Tabela 2

Análise de cluster

\begin{tabular}{|c|c|c|c|c|c|}
\hline Cluster & $\mathrm{n}$ & $\%$ & média & $\mathrm{dp}$ & $\mathrm{cv}$ \\
\hline Muito forte & 154 & 13,2 & 6,39 & 0,564 & 0,088 \\
\hline Forte & 298 & 25,4 & 4,34 & 0,475 & 0,109 \\
\hline Médio & 445 & 38,0 & 2,52 & 0,500 & 0,198 \\
\hline Fraco & 274 & 23,4 & 0,61 & 0,488 & 0,800 \\
\hline Total & 1.171 & 100,0 & 3,05 & 1,91 & 0,626 \\
\hline
\end{tabular}

$\mathrm{dp}=$ desvio-padrão; $\mathrm{cv}$ = coeficiente de variação.

O grupo que coopera muito fortemente é formado por 154 observações (13,2\%), tem uma média de cooperação de 6,39 votos e um desvio-padrão de 0,564. No outro oposto, o grupo que coopera de forma fraca é composto por 274 ocorrências (23,4\%), tem uma média de votos de 0,61 e um desvio-padrão de 0,488. Comparativamente, no que diz respeito à heterogeneidade dos grupos, o grupo fraco apresenta a distribuição mais assimétrica com um coeficiente de variação de 0,800 , enquanto o grupo muito forte é o mais homogêneo $(0,088)$. Em termos substantivos, isso quer dizer que os deputados agrupados no cluster muito forte são mais parecidos entre si quando comparados com os parlamentares conglomerados no cluster de cooperação fraca.

Manoel Leonardo Santos·manoelsantos@fafich.ufmg.br

Mariana Batista da Silva · mariana.bsilva@gmail.com

Dalson Britto Figueiredo Filho -dalsonbritto@yahoo.com.br

Enivaldo Carvalho Rocha ·enivaldocrocha@gmail.com

Submetido à publicação em março de 2014.

Versão final aprovada em novembro de 2014. 